\title{
CƠ CHẾ BẢO ĐẢM QUYỀN CỦA NGƯờI DÂN TộC THIỂU SỐ Ở VIẸT NAM HIỆN NAY
}

The ensure mechanism on the ethnic minority people's rights in Vietnam nowadays Ngày nhận bài: 29/2/2017; ngày phản biện: 10/3/2017; ngày duyệt đăng: 22/3/2017

\section{Đỗ Mạc Ngân Doanh*}

\section{TÓM TẮT}

Trong bối cảnh mà pháp luật nhân quyền quốc tế và cơ chế đa phương nhằm bảo vệ quyền con người, quyền của người thiểu số còn thể hiện những khoảng trống và điểm thiếu hụt đáng kể, hoàn thiện và thúc đẩy hiệu quả của cơ chế bảo vệ quyền của người dân tộc thiểu số tại mỗi quốc gia đa dân tộc có lẽ là đích đến phù hợp nhất trong thời điểm hiện nay. Có thể nhận định, tại Việt Nam, cơ chế bảo đảm, ghi nhận, bảo vệ và thực thi quyền của người dân tộc thiểu số hiện nay có cấu trúc tương thích rất cao so với các tiêu chuẩn quốc tế, thậm chí là tiến bộ và có mức độ ưu đãi, hỗ trợ rất lớn. Theo đó, bảo đảm quyền con người ở các vùng dân tộc thiểu số đã được Đảng và Nhà nước quan tâm sâu sắc, thể hiện qua hệ thống chính sách và pháp luật hầu như đã bao kín tất cả các lĩnh vực từ kinh tế, xã hội, văn hóa; dân sự và chính trị cho đến các vấn đề đặc thù của thiểu số. Bài viết sau đây sẽ làm rõ khái niệm thực thi cơ chế bảo đảm quyền của người dân tộc thiểu số ở Việt Nam hiện nay.

Từ khóa: quyền con người; quyền của người dân tộc thiểu số; dân tộc thiểu số; cơ chế bảo đảm về nhân quyền

\section{ABSTRACT}

In the context of international human rights law and multilateral mechanisms to protect human rights, rights of minorities shows gaps, improve and promote the effectiveness of mechanisms to protect the rights of ethnic minorities in each multiethnic country is perhaps the most appropriate destination for the present time. In Vietnam, ensuring mechanisms, recognition, protection and enforcement of rights of ethnic minorities are now compatible to international standards. Accordingly, ensuring human rights in ethnic minority areas have been deeply concerned by the Party and State, expressed through a system of policies and laws have sealed almost all the economic, social and cultural; civil and political sectors to the specific issues of minorities. The following article, in addition to clarifying the content mentioned above will continue to offer practical problems, has been set for the promotion of enforcement mechanism to ensure the rights of ethnic minorities in Vietnam nowadays.

Keywords: human rights; rights of ethnic minorities; ethnic minorities; ensure mechanism on human rights

1. Khái niệm về cơ chế bảo đảm quyền con người, quyền của người dân tộc thiểu số

- "Cơ chế": Theo từ điển tiếng Anh [5; tr.1148] và tiếng Việt [4], thuật ngữ "cơ chế" (mechanism) thường được định nghĩa là hệ thống các bộ phận hoạt động cùng nhau trong một bộ máy; hoặc là một quá trình tự nhiên hay thiết lập, mà nhờ đó một hoạt động nào đó

*Sở Khoa học \& Công nghệ tỉnh Tuyên Quang 
được tiến hành và được thực hiện. Theo những hướng khác nhau, nội hàm thuật ngữ "cơ chế" có thể được bao gồm bởi những thuộc tính khác nhau. Nói chung, thông thường "cơ chế" luôn gắn liền với hoạt động của một hệ thống, do đó mà nội hàm thuật ngữ cơ chế cũng bao gồm hai nội dung: một là cấu trúc của một chỉnh thể gồm nhiều bộ phận khác nhau hợp thành có mối liên hệ mật thiết với nhau và hai là phương thức hoạt động của chỉnh thể đó nhằm đạt được một kết quả nhất định.

- "Cơ chế bảo đảm quyền con người": Trong khoa học lý luận về nhà nước và pháp luật, tồn tại khái niệm "cơ chế điều chỉnh pháp luật", trong đó "cơ chế bảo đảm quyền" là một ngoại diên của khái niệm đó. Dưới tiếp cận của quyền con người, một nội dung cơ bản, quan trọng và không thể thiếu trong hệ thống pháp luật của nhà nước pháp quyền, ở phạm vi quốc gia hay quốc tế cũng đều cần cơ chế bao quát được tất cả yếu tố của pháp luật về quyền con người. Đó chính là co chế tôn trọng, thúc đẩy và bảo vệ quyền con người, trong đó bao gồm hệ thống các nguyên tắc, qui phạm pháp luật quốc tế và các thiết chế quốc tế trong mối quan hệ tác động qua lại với nhau nhằm bảo đảm quyền con người [7].

- "Cơ chế bảo đảm quyền của người dân tộc thiểu số (QCNDTTS)": Cơ chế bảo đảm quyền của người dân tộc thiểu số là một hệ thống thể chế và thiết chế đặc thù đối với một nhóm đối tượng dễ bị tổn thương là người dân tộc thiểu số, nằm trong hệ thống cơ chế bảo đảm quyền con người hiện nay. Xét về phạm vi, cũng giống như mức độ phổ quát của quyền con người nói chung, cơ chế này cũng bao gồm hệ thống ở cấp độ quốc tế đa phương; khu vực và ở mỗi quốc gia cụ thể. Cơ chế bảo đảm và bảo vệ QCNDTTS ở cấp độ quốc tế dựa trên hệ thống văn kiện quốc tế về quyền của người thiểu số, được Liên hợp quốc thông qua như: ICERD; ICCPR; ICESCR; CRC và có các cơ quan có chức năng bảo đảm, tôn trọng, bảo vệ, thúc đẩy thực hiện. Ở từng khu vực địa lý (theo châu, theo khu vực) cơ chế bảo đảm, bảo vệ quyền con người của châu Âu, châu Mỹ, châu Phi; cơ chế bảo đảm nhân quyền của khu vực Đông Nam Á có những hướng đi riêng trong bảo đảm quyền, do sự khác biệt về nhu cầu của người thiểu số ở khu vực mình.

Tại mỗi quốc gia, tùy thuộc vào điều kiện kinh tế, xã hội, chính trị, lịch sử và truyền thống mà họ xây dựng mô hình cơ chế bảo đảm, bảo vệ quyền của người thiểu số trên cơ sở phải tuân thủ cơ chế bảo đảm, bảo vệ và thúc đẩy quyền con người của khu vực và quốc tế. Nếu như tại Hợp chủng quốc Hoa Kỳ, vấn đề chống phân biệt đối xử về chủng tộc đối với người thiểu số được đề cập trong $\mathrm{Tu}$ chính án thứ 14, 15 của Hiến pháp năm 1787; trong Đạo luật về quyền bầu cử năm 1965 và đạo luật về đăng ký cử tri quốc gia năm 1994 [9]. Thì tại New Zealand, vấn đề của người Maori được đề cập trong đạo luật của Nghị viện New Zealand năm 1975 và nhiều chính sách về văn hóa. Tại Trung Quốc, một số quyền của các dân tộc thiểu số được ghi nhận tại Hiến pháp năm 1982, trong đó các dân tộc thiểu số có số dân đông đáng kể được ghi nhận quyền tự trị trong Phần thứ 6 của và Luật tự trị khu vực dân tộc năm 1984 (sửa đổi năm 2001), các dân tộc thiểu số ít người hơn chỉ được đề cập đến trong Chương trình chung năm 1949. Tại khu vực châu Âu, mặc dù nhận được mối quan tâm lớn và những điều khoản khắt khe về người thiểu số khi gia nhập liên minh, nhưng hành xử của các quốc gia thành viên cũng khác nhau. Nếu Slovakia đã ghi nhận các quyền phát triển văn hóa của người thiểu số tại Hiến pháp năm 1992, trong Luật về sử dụng ngôn ngữ thiểu số năm 1999 và Luật chống phân biệt đối xử năm 2004 thì tại Hy Lạp vẫn tồn tại những lỗ hổng pháp lý đối với một loạt các vấn đề của người nhập cư [9]. 
Khu vực Đông Nam Á có nhiều điểm chung hơn khi hầu hết các quốc gia đã nỗ lực ghi nhận quyền của các nhóm thiểu số trong Hiến pháp của mình. Tuy nhiên do khác biệt cả về đối tượng hưởng quyền, thể chế chính trị và hệ thống tòa án... sự ghi nhận đó vẫn được biểu hiện bởi những nội dung rất đa dạng. Nhu cầu về quyền của các nhóm thiểu số khác nhau càng thể hiện rõ hơn điều đó: tại Indonesia, Malaysia là vấn đề của người thiểu số về tôn giáo (do Hồi giáo chiếm ưu thế); Philippines với vấn đề đặc thù của dân số đa số là người Philippines gốc Tây Ban Nha; Thái Lan với vấn đề về đẳng cấp xã hội của người thiểu số ở Nam và Bắc Thái Lan; Lào, Campuchia và Việt Nam với các vấn đề về phát triển và giảm nghèo của người thiểu số... Nhìn chung thì cơ chế bảo đảm quyền mang tính nhà nước tại mỗi quốc gia thông thường được đề cập đến bởi hai thành tố cơ bản: Thể chế và thiết chế tổ chức thực hiện.

\section{Thể chế bảo đảm quyền của người dân tộc thiểu số ở Việt Nam hiện nay}

Cũng giống như cách hiểu ở nhiều quốc gia trên thế giới, Hiến pháp hiện hành ở Việt Nam cũng là một hệ thống quy định cơ bản về những nguyên tắc chính trị của quyền lực nhà nước và về việc thiết lập kiến trúc thượng tầng, quyền hạn và trách nhiệm của tổ chức bộ máy nhà nước, sự bảo đảm các quyền và tự do cơ bản của con người và của công dân. Việc ghi nhận, bảo vệ và thực hiện QCNDTTS ở Việt Nam là một chính sách nhất quán, được quy định trong Hiến pháp và pháp luật, tạo cơ sở bảo đảm cho người dân tộc thiểu số được tiếp cận quyền trên tất cả các lĩnh vực kinh tế, dân sự, chính trị, văn hoá và xã hội. Việt Nam đã tham gia và phê chuẩn cả 4 công ước quốc tế có đề cập và liên quan chặt chẽ đến vấn đề thiểu số (ICCPR; ICESCR; ICERD; CRC), đây là những điều kiện để Việt Nam tiệm cận và đặt mình vào trong khuôn khổ chung của pháp luật quốc tế về quyền con người.

Định hướng của công tác dân tộc, chính sách và pháp luật về bảo đảm quyền của người dân tộc thiểu số xác định tại Điều 5 Hiến pháp hiện hành: "1. Nước Cộng hòa xã hội chủ nghĩa Việt Nam là quốc gia thống nhất của các dân tộc cùng sinh sống trên đất nước Việt Nam. 2. Các dân tộc bình đẳng, đoàn kết, tôn trọng và giúp nhau cùng phát triển; nghiêm cấm mọi hành vi kỳ thị, chia rẽ dân tộc. 3 . Ngôn ngũu quốc gia là tiếng Việt. Các dân tộc có quyền dùng tiếng nói, chũu viết, giữ gìn bản sắc dân tộc, phát huy phong tục, tập quán, truyền thống và văn hóa tốt đẹp của mình. 4 . Nhà nước thực hiện chính sách phát triển toàn diện và tạo điều kiện để các dân tộc thiểu số phát huy nội lực, cùng phát triển với đất nước" [1]. Định hướng này hoàn toàn phù hợp với nội dung của các công ước quốc tế mà Việt Nam đã tham gia và hướng dẫn của pháp luật quốc tế về bảo đảm quyền của người dân tộc thiểu số. Quyền bình đẳng và chống phân biệt đối xử được đề cập đến tại Điều $7 ; 16 ; 24 ; 26 ; 35 ; 36$; $38 ; 59$ và một số vấn đề liên quan tới các vấn đề đặc thù tại vùng sinh sống của người dân tộc thiểu số như Điều 36 (về hôn nhân theo nguyên tắc tự nguyện, tiến bộ); Điều 37 (về các vấn đề về quyền trẻ em tại Khoản 1 và quyền của thanh niên tại Khoản 2); Khoản 3 Điều 62 (về việc tạo điều kiện để thụ hưởng lợi ích từ các hoạt động khoa học và công nghệ); Điều 63 (về quản lý, sử dụng hiệu quả, bền vững các nguồn tài nguyên thiên nhiên).

Quy định về lĩnh vực dân tộc, công tác dân tộc cụ thể tại các Điều 42, 58, 60, 61, 75 của Hiến pháp 2013, cụ thể: về quyền xác định dân tộc, sử dụng ngôn ngữ của đồng bào dân tộc thiểu số được quy định tại Điều 42; về lĩnh vực y tế, chăm sóc sức khỏe tại khoản 1 Điều 58 ; về an sinh xã hội, mặc dù không trực tiếp đề cập đến các đối tượng dễ bị tổn thương 
nhưng Hiến pháp đã ghi nhận và tạo cơ hội để bất cứ ai cũng có quyền được bảo đảm an sinh xã hội, khẳng định tại một điều riêng, đó là Điều 34; về lĩnh vực văn hóa, tại khoản 1 Điều 60; về lĩnh vực giáo dục tại Điều 61; vấn đề "lao động trẻ em" tại các vùng sinh sống chủ yếu của người dân tộc thiểu số, tại Khoản 3 Điều 35; về vị trí, vai trò, chức năng, nhiệm vụ của Hội đồng và Chủ tịch Hội đồng dân tộc được làm rõ hơn, đề cao vai trò, trách nhiệm, quy định tại khoản 2, khoản Điều 75 [1].

Dưới Hiến pháp, bảo đảm quyền của người dân tộc thiểu số ở Việt Nam thể hiện trong nhiều đạo luật, qua thống kê về một số nội dung và nhu cầu bảo đảm quyền con người của người dân tộc thiểu số cũng có thể thấy được mức độ che phủ khá toàn diện và mức độ tương thích cao với pháp luật quốc tế về quyền con người.

Bên cạnh Hiến pháp và pháp luật hiện hành, Nhà nước Việt Nam đã có một hệ thống chính sách về hỗ trợ phát triển cho người dân tộc thiểu số với khoảng 183 chính sách, được thể chế qua 264 văn bản, bao trùm toàn bộ đời sống chính trị kinh tế văn hóa của người dân tộc thiểu số [6]. Trong lĩnh vực dân tộc ngoài Nghị định số 05/2011/NĐ-CP ngày 14/01/2011 của Chính phủ về Công tác dân tộc vẫn là văn bản có giá trị pháp lý cao nhất, các văn bản pháp lý thực hiện chính sách mới thể hiện bằng các Quyết định của Thủ tướng Chính phủ, chưa có văn bản pháp luật cao hơn. Bên cạnh đó, Chương trình hành động thực hiện Chiến lược công tác dân tộc đến năm 2020 đã được Thủ tướng Chính phủ phê duyệt tại Quyết định số 449/QĐ-TTg ngày 12/03/2013 đã tiếp tục hiện thực hóa việc bảo đảm QCNDTTS. Những quy định nêu trên là cơ sở pháp lý quan trọng, đặt nền móng cho việc xây dựng Đề án Luật dân tộc theo Chiến lược Công tác dân tộc đến năm 2020 được Thủ tướng Chính phủ phê duyệt đồng thời thể hiện nỗ lực của Nhà nước Việt Nam trong bảo đảm quyền con người, quyền của người dân tộc thiểu số trong thời gian tới.

\section{Thiết chế bảo đảm quyền của người dân tộc thiểu số ở Việt Nam hiện nay}

Mặc dù Việt Nam chưa có được một cơ quan nhân quyền quốc gia nhưng đã có các cơ quan nhà nước thực hiện chức năng giải quyết các vấn đề dân tộc đặc thù như: Hội đồng dân tộc của Quốc hội; Ủy ban dân tộc của Chính phủ và các Ban dân tộc ở địa phương.

Về nội dung bảo đảm chung, cơ chế nhà nước thường bao gồm: Quy trình ngân sách quốc gia; Xây dựng năng lực của chính phủ; Cân đối khung tiêu chuẩn quốc tế và quốc gia về chỉ số quyền con người và đăng ký hành chính về nhân quyền; Chương trình - Chính sách quốc gia về hỗ trợ kinh tế - xã hội và văn hóa cho đồng bào ở những vùng có điều kiện khó khăn... đó cũng là các chương trình hỗ trợ mà không phải quốc gia đang phát triển nào cũng có được. Cơ chế bảo đảm QCNDTTS của nhà nước ta hiện nay có thể đánh giá là khá hoàn chỉnh về mặt thể chế và thiết chế. Các cơ quan lập pháp; cơ quan tư pháp và Tòa án; các cơ quan hành chính nhà nước và các ban chỉ đạo về vấn đề bảo đảm quyền của người dân tộc thiểu số của Chính phủ ở cấp TƯ lần lượt mang chức năng tôn trọng, bảo vệ và thúc đẩy việc thực hiện quyền của người dân tộc thiểu số; các cơ quan hành chính nhà nước, cơ quan tư pháp và tòa án ở cấp địa phương lần lượt mang chức năng thực hiện và bảo vệ quyền của người dân tộc thiểu số tại địa phương mình, có tham chiếu các quy định của pháp luật quốc tế.

Ngoài ra, nếu xét theo nhánh các cơ chế tôn trọng (ghi nhận và giám sát thực thi quyền), bảo vệ và thúc đẩy thực thi quyền thì có thể nhận diện thiết chế bảo đảm quyền của người dân tộc thiểu số ở Việt Nam với những vai trò sau:

- Thiết chế ghi nhận và giám sát thực thi quyền: Nếu như cơ sở quan trọng cần phải có 
trước tiên để bảo vệ quyền con người, quyền của người dân tộc thiểu số tại một quốc gia đa dân tộc là sự ghi nhận quyền con người, quyền của người dân tộc thiểu số trong Hiến pháp thì Quốc hội là mắt xích đầu tiên trong hệ thống các thiết chế bảo đảm quyền con người. Đối với vấn đề dân tộc nói chung, bảo đảm QCNDTTS nói riêng, Quốc hội giao cho một cơ quan chuyên trách đảm nhiệm là Hội đồng dân tộc kể từ năm 1992. Hiện nay Hội đồng dân tộc là cơ quan có vai trò bảo đảm chung và giám sát hoạt động bảo đảm quyền của người dân tộc thiểu số được thực hiện, bao gồm cả các nội dung cơ bản về quyền con người (về dân sự - chính trị, kinh tế - xã hội - văn hóa) và cả các nội dung đặc thù về quyền của người dân tộc thiểu số. Hội đồng Dân tộc Việt Nam là cơ quan chịu trách nhiệm của Quốc hội, có chức năng giám sát hoạt động của Chính phủ, Nhà nước về các vấn đề dân tộc, đồng thời là cơ quan tham mưu về chính sách, nghị định cho Ủy ban Dân tộc và Chính phủ. Hội đồng Quốc hội còn giám sát hoạt động của các Ban Dân tộc tại các địa phương, về ngân sách, chính sách, quyết định của Ủy ban Nhân dân, Hội đồng Nhân dân các tỉnh và thành phố.

- Thiết chế thực thi quyền: Cơ chế quan trọng nhất có chức năng thúc đẩy các vấn đề nhằm bảo đảm QCNDTTS hiện nay là Ủy ban Dân tộc_ cơ quan ngang bộ thuộc Chính phủ. Chức năng, nhiệm vụ, quyền hạn và cơ cấu tổ chức của cơ quan quản lý chuyên trách về công tác dân tộc của Chính phủ được quy định tại Nghị định số 84/2012/NĐ-CP ngày 12/10/2012. Có thể đánh giá, về mặt cơ cấu, Ủy ban dân tộc là một thiết chế được xây dựng nhiệm vụ và chức năng khá toàn diện, có đủ điều kiện về mặt cơ cấu để đảm nhiệm nhiệm vụ bảo đảm và thúc đẩy thực hiện quyền con người, trong đó, cơ cấu tổ chức đã chú ý tới tính đặc thù của vấn đề dân tộc tại các vùng miền. Ưy ban Dân tộc có các ủy viên kiêm nhiệm là đại diện Lãnh đạo một số Bộ, ngành, cơ quan Trung ương [3] (hiện nay có 7 đồng chí Ủy viên kiêm nhiệm là Thứ trưởng các Bộ Kế hoạch và Đầu tư; Nông nghiệp và Phát triển Nông thôn; Lao động Thương binh và Xã hội; Văn hóa - Thông tin, Giáo dục và Đào tạo; Nội vụ và Phó trưởng Ban tôn giáo của Chính phủ) do đó có thể tiếp nhận các ý kiến tham mưu về tất cả các lĩnh vực kinh tế, xã hội, văn hóa và dân sự, chính trị về quyền của người dân tộc thiểu số cũng như nắm được thực trạng về nhu cầu và mức độ bảo đảm quyền. Hệ thống cơ quan công tác dân tộc tại địa phương được quy định tại Nghị định số 53/2004/NĐ-CP ngày 18/02/2004 về kiện toàn tổ chức bộ máy làm công tác dân tộc thuộc Ủy ban nhân dân các cấp, thực hiện theo nguyên tắc của Nghị quyết Hội nghị lần thứ 7 Ban Chấp hành Trung ương (khóa IX) về công tác dân tộc [2]. Theo đó, việc tổ chức đơn vị chuyên trách quản lý nhà nước về dân tộc ở địa phương chỉ thực hiện ở hai cấp là cấp tỉnh và cấp huyện.

Ngoài ra, Chính phủ còn có một hệ thống các cơ quan mang chức năng quản lý liên ngành, bảo đảm sự bình đẳng và chống phân biệt đối xử trong việc thực hiện các quyền con người đối với người dân tộc thiểu số trên tất cả các lĩnh vực: dân sự, chính trị, kinh tế, xã hội và văn hóa. Đó là 18 bộ, cơ quan ngang bộ bao gồm: Bộ Quốc phòng; Bộ Công an; Bộ Ngoại giao; Bộ Tư pháp; Bộ Tài chính; Bộ Công thương; Bộ Lao động, Thương binh và Xã hội; Bộ Giao thông vận tải; Bộ Xây dựng; Bộ Thông tin và Truyền thông; Bộ Giáo dục và Đào tạo; Bộ Nông nghiệp và Phát triển nông thôn; Bộ Kế hoạch và Đầu tư; Bộ Nội vụ; Bộ Y tế; Bộ Khoa học và Công nghệ; Bộ Văn hóa, Thể thao và $\mathrm{Du}$ lịch; Bộ Tài nguyên và Môi trường.

- Thiết chế bảo vệ quyền (Tòa án và Viện kiểm sát): Dưới hiến pháp, cơ chế tòa án bảo vệ quyền con người, quyền của người dân tộc thiểu số bằng tố tụng hình sự; dân sự; hành chính hiện được quy định tại: Bộ luật tố tụng 
hình sự; Bộ luật tố tụng dân sự và Luật tố tụng hành chính Việt Nam và được bảo đảm thực hiện bằng hệ thống Tòa án (thẩm quyền của Tòa án đối với từng trường hợp quy định trong luật). Ở Việt Nam, Viện kiểm sát là cơ quan duy nhất được giao chức năng thực hành quyền công tố và kiểm sát các hoạt động tư pháp. Hoạt động công tố và kiểm sát điều tra được thực hiện ngay từ khi khởi tố vụ án hình sự và trong suốt quá trình điều tra các vụ án hình sự.

Đặc biệt, chuyển biến mạnh mẽ của các cơ chế pháp lý cho phép sự tham gia trực tiếp của người dân trong việc giám sát đối với hoạt động của nhà nước trong lĩnh vực thực hiện quyền con người là những thành quả rất đáng kể. Việt Nam cũng đang bắt đầu thí điểm những mô hình Tòa án mang tính chất bảo vệ quyền con người theo hướng phù hợp với văn hóa và dân trí người dân như mô hình Tòa án gia đình và người chưa thành niên (Tòa án cấp thành phố, thí điểm tại TP. Hồ Chí Minh).
Sự vắng mặt của một cơ chế nhân quyền quốc gia (hay Tòa án Hiến pháp) có khả năng giải quyết các khiếu nại nhân quyền mang tính độc lập, có chuyên môn cao và thẩm quyền rộng vẫn đưa đến những vấn đề cần giải quyết. Trong đó bao gồm sự hoài nghi về mức độ công khai, minh bạch trong giải quyết các vấn đề về quyền con người, quyền công dân, đặc biệt là trong các vi phạm nhân quyền có sự liên quan đến các chủ thể mang tính quyền lực; sự va chạm về thẩm quyền khi xử lý các vấn đề khi bên có vi phạm nhân quyền là tổ chức, cơ quan, đoàn thể hay thậm chí là Hiến pháp và pháp luật... Mặc dù vậy, cơ chế đặc thù hiện có mang chức năng bảo đảm các QCNDTTS hiện có của nhà nước ta là một cơ chế có kết cấu khá ổn định và phù hợp với sự phát triển kinh tế - xã hội và văn hóa nhân quyền ở nước ta trong giai đoạn này. Điều quan trọng hơn tiếp theo cần được quan tâm xem xét đó là mức độ hiện thực hóa, phù hợp trong chi tiêu và đáp ứng được nhu cầu của người dân tộc thiểu số của hệ thống chính sách dân tộc ở Việt Nam hiện nay.

Để đáp ứng được điều này, minh bạch hóa và tăng cường đối thoại vẫn được cho là hướng đi phù hợp./.

\section{TÀI LIỆU THAM KHẢO}

1. Hiến pháp nước Cộng hòa xã hội chủ nghĩa Việt Nam 2013 được Quốc hội nước Cộng hòa xã hội chủ nghĩa Việt Nam thông qua ngày 28 tháng 11 năm 2013;

2. Nghị định số 53/2004/NĐ-CP ngày 18/02/2004 về kiện toàn tổ chức bộ máy làm công tác dân tộc thuộc Ủy ban nhân dân các cấp;

3. Nghị định số 84/2012/NĐ-CP của Chính phủ: Quy định chức năng, nhiệm vụ, quyền hạn và cơ cấu tổ chức của Ủy ban Dân tộc;

4. Trung tâm Từ điển học - Viện ngôn ngữ học (1997), Tư điển Tiếng Việt, Nxb Đà Nẵng;

5. Oxford University (1998), The New Oxford Dictionary of English, Claren Press, Oxford;

6. Bế Thị Hồng Vân - Phó Vụ trưởng Vụ chính sách của UBDT, Báo cáo của UBDT tại Hội thảo Liệu miền núi có cần tiến kịp miền xuôi ngày 17/10/2015, Army Hotel, Hà Nội, 2015;

7. Võ Khánh Vinh - Lê Mai Thanh (chủ biên) (2014), Cơ chế quốc tế và khu vực về quyền con người, Nxb Khoa học Xã hội, Hà Nội;

8.http://asiapacificforum.net/about/annual-meetings/12th-australia-2007/downloads/regionalcooperation-between-nhris/Declaration\%20of\%20Cooperation.pdf

9. http://minorityrights.org 